\title{
IDENTIFICAÇÃO AUTOMÁTICA DE UTILIZADORES COM DEFICIÊNCIA VISUAL: A BASE PARA UM SERVIÇO DE ÁUDIO DESCRIÇÃO PERSONALIZADO
}

\author{
Oliveira, Rita ${ }^{1}$ \\ Silva, Telmo ${ }^{2}$ \\ Abreu, Jorge Ferraz de ${ }^{3}$ \\ Almeida, Ana Margarida ${ }^{4}$ \\ CETAC.MEDIA - Universidade de Aveiro \\ ritaoliveira@ua.pt \\ tsilva@ua.pt \\ ja@ua.pt \\ marga@ua.pt
}

\begin{abstract}
Material original autorizado para su primera publicación en la revista académica REDMARKA. Revista Digital de Marketing Aplicado

https://doi.org/10.17979/redma.2011.03.07.4742
\end{abstract}

Recibido: 16 Noviembre 2011

Aceptado: 1 Diciembre 2011

\footnotetext{
${ }^{1}$ Bolseira de Doutoramento da FCT (Fundação para a Ciência e a Tecnologia) na unidade de investigação CETAC.MEDIA (Centro de Estudos das Tecnologias e Ciências da Comunicação) e frequenta o Programa Doutoral em ICPD (Informação e Comunicação em Plataformas Digitais), lecionado em parceria pela Universidade de Aveiro e pela Universidade do Porto. A sua área de investigação está ligada ao desenho e desenvolvimento de serviços interativos televisivos ajustados a utilizadores com necessidades especiais.

${ }^{2}$ Assistente no Departamento de Comunicação e Arte da Universidade de Aveiro, colaborador da unidade de investigação CETAC.MEDIA (Centro de Estudos das Tecnologias e Ciências da Comunicação) e frequenta o Programa Doutoral em ICPD (Informação e Comunicação em Plataformas Digitais), lecionado em parceria pela Universidade de Aveiro e pela Universidade do Porto. A sua área de investigação está ligada ao desenho e desenvolvimento de serviços de televisão interativos, essencialmente baseados em plataformas IPTV.

${ }^{3}$ Professor Auxiliar no Departamento de Comunicação e Arte da Universidade de Aveiro e membro da unidade de investigação CETAC.MEDIA (Centro de Estudos das Tecnologias e Ciências da Comunicação). A sua área de investigação está ligada aos novos media, a conteúdos multiplataforma e à Televisão Interativa, com particular interesse no desenvolvimento e avaliação de aplicações de Social iTV.

${ }^{4}$ Professora Auxiliar no Departamento de Comunicação e Arte da Universidade de Aveiro e membro da unidade de investigação CETAC.MEDIA (Centro de Estudos das Tecnologias e Ciências da Comunicação). A sua área de investigação está ligada à inclusão digital, ao acesso universal aos media e às tecnologias da comunicação e informação no apoio a cidadãos com necessidades especiais.
} 


\section{RESUMO}

Os serviços de áudio descrição (AD) interativos, atualmente existentes, podem ser alvo de um conjunto de melhorias com vista a uma adequação mais eficiente ao contexto dos utilizadores com deficiência visual. Na realidade, as funcionalidades interativas inerentes a estes serviços, suportados por diferentes plataformas de televisão, centram-se, maioritariamente, na opção de ativação da áudio descrição e de alertas sonoros quando um programa com áudio descrição é iniciado. Contudo, as infraestruturas de distribuição de televisão atuais, desde que complementadas com um canal de retorno e SetTop Boxes (STB) adequadas, abrem uma janela de oportunidade bastante interessante para a criação de um serviço interativo de áudio descrição que integre funcionalidades avançadas que possam ser, automaticamente, ajustadas às preferências dos utilizadores.

É neste contexto que se propõe o desenvolvimento de um serviço interativo de áudio descrição complementado por um sistema de identificação automática do utilizador. Com esta complementaridade, o serviço pode ser dinamicamente ajustado às preferências do utilizador que, de facto, está a ver televisão, invocando, automaticamente, as opções previamente selecionadas nas respetivas configurações.

Uma vez que existem diversas formas de implementar um sistema de identificação, realizaram-se um conjunto de entrevistas, no Instituto Oftalmológico Dr. Gama Pinto - IOGP, em Lisboa, com o objetivo de determinar o método de identificação mais adequado para utilizadores com deficiência visual. As entrevistas foram realizadas a 20 utentes da consulta de sub-visão.

A partir dos resultados obtidos foi possível concluir que existe uma preferência por dois métodos de identificação, nomeadamente o uso de um cartão RFID e de um leitor de impressões digitais. 
Palavras-chave. Televisão Interativa, Áudio Descrição, Identificação do Utilizador

\author{
ABSTRACT \\ AUTOMATIC IDENTIFICATION OF VISUALLY IMPAIRED USERS: FOUNDATIONS FOR A \\ COSTUMIZED AUDIO DESCRIPTION SERVICE
}

The interactive audio description (AD) services, which currently exist, may be subject to a set of improvements in order to provide a more efficient adjustment to the visually impaired users' context. Actually, the interactive features inherent to these services, supported by different television platforms, focus mainly in audio description activation option and alerts when a program with audio description is started. However, the existing television broadcasting infrastructures, if they are complemented with a return channel and adapted Set-Top Boxes (STB), strengthen the interesting opportunity to create an interactive audio description $(A D)$ service that integrates advanced features that can be automatically adjusted to users' preferences.

It is in this context that we propose the development of an interactive audio description service, which is complemented with a user automatic identification system. With this complementary approach, the service can be dynamically adjusted to the preferences of the user who is in fact watching television, invoking, automatically, the options that were previously selected in the related configurations.

Once that are different ways to implement an identification system, it was carried out a set of interviews, at Instituto Oftalmológico Dr. Gama Pinto IOGP, in Lisbon, in order to determine the most suitable identification method for visually impaired users. The interviews were carried out to 20 patients of the low vision appointment.

From the obtained results, it was possible to conclude that there is a tendency for two identification methods, namely the use of an RFID card and a fingerprint reader. 
Key words. Interactive Television, Audio Description, User Identification 


\section{Introdução}

Apesar da crescente democratização das tecnologias de informação e comunicação (TIC), verifica-se que os cidadãos com necessidades especiais continuam vulneráveis ao fenómeno da infoexclusão, sendo fundamental a criação de estratégias de inclusão para o aumento da literacia digital e das capacidades de participação destes cidadãos em diferentes domínios.

No que diz respeito ao domínio da Televisão, ao longo dos últimos anos, esta tem sofrido alterações técnicas que permitem uma transição no comportamento dos telespectadores, passando estes a beneficiarem de um meio interativo com imensas potencialidades. Esta alteração inerente ao conceito de Televisão Interativa (iTV) possibilita aos telespectadores a utilização de novos serviços, nos quais podem assumir um papel mais ativo e participativo.

No entanto, como estes serviços envolvem, tipicamente, uma forte componente visual (é necessário ler instruções no ecrã e selecionar opções com o comando televisivo), apresentam dificuldades acrescidas de interação por parte de utilizadores idosos e com deficiência visual (UDV). Em resultado, para além dos problemas no acesso ao conteúdo televisivo, estes utilizadores possuem dificuldades acrescidas ou podem mesmo ficar impossibilitados de aceder e utilizar serviços iTV.

Um ecrã de TV com baixa resolução pode dificultar a distinção de cores, formas, informações gráficas ou informações em movimento. Assim, para que a experiência de interação deste tipo de utilizadores seja melhorada, a legibilidade destes recursos deve ser uma das preocupações do designer aquando da conceção e do desenho da interface (Tiresias, 2009a). Não obstante, os UDV podem utilizar ajudas técnicas quando fazem uso de serviços iTV, tais como aparelhos de aumento visual, ou podem mesmo sentar-se mais próximos do televisor.

Por outro lado, os utilizadores cegos preferem que a sua interação com estes serviços seja acompanhada por ajudas auditivas, no entanto estes sistemas 
existem ainda em número reduzido e são dispendiosos (Tiresias, 2009a). Um exemplo deste tipo de sistema é descrito na seção '5.2. Smart Talks'.

Algumas investigações sobre o uso da iTV por pessoas com baixa visão indicam que este grupo de utilizadores é muito heterogéneo em termos de patologias, logo é difícil otimizar um único design de interfaces que vá ao encontro de todas as especificidades e necessidade deste tipo de utilizadores (Tiresias, 2009b). Ao serem adicionadas opções de personalização à interface, o sistema torna-se inevitavelmente mais acessível e com a capacidade de responder às dificuldades de um leque mais vasto de utilizadores com baixa visão. Desta forma a personalização da interface poderia, por exemplo, permitir aos utilizadores o controlo do tamanho do texto, do layout de conteúdos, do volume do feedback sonoro, dos esquemas de cores, do tamanho das legendas, das opções associadas à áudio descrição, entre outros.

A identificação automática de utilizadores, aplicada a um serviço iTV deste tipo, mostra ser uma solução útil, na medida em que o utilizador necessita apenas de configurar o seu perfil uma única vez para que, posteriormente, o sistema reconheça automaticamente as opções associadas ao utilizador. Para além desta vantagem, cada membro da família pode também criar o seu perfil, não modificando as preferências dos restantes membros.

Neste contexto, o presente artigo apresenta uma investigação que tem, entre outros, o objetivo de determinar os métodos de identificação de utilizador mais ajustados para um serviço avançado de áudio descrição, baseado em princípios de design universal.

Inicialmente, começa-se por identificar algumas modalidades de AD, clarificando os vários ambientes e contextos em que esta pode ser aplicada. Após esta descrição, é efetuada uma abordagem ao uso da AD em Portugal, tendo em consideração as diferentes modalidades existentes no país, seguindo-se a apresentação do estado de implementação da AD noutros países. De seguida, são apresentados alguns serviços iTV de áudio descrição e discutem-se aspetos e questões ligadas à identificação de utilizadores, 
nomeadamente em televisão. Por fim, descreve-se o processo de investigação, designadamente a técnica de recolha de dados adotada e os resultados relacionados com as questões sobre a componente de identificação automática e as respetivas conclusões.

\section{Modalidades de Áudio Descrição}

A áudio descrição, sendo uma técnica flexível, é suscetível de aplicação em vários espaços e contextos, apenas sendo necessário adequar os métodos e as tecnologias às características e especificidades desse espaço/contexto. Por esse motivo são várias as modalidades de áudio descrição que existem. De seguida são abordadas algumas modalidades de $A D$, nomeadamente na Televisão, na Web, no Cinema e no Teatro.

\subsection{Na Televisão}

Genericamente, a áudio descrição em TV baseia-se numa faixa de áudio que é adicionada à transmissão televisiva e que descreve verbalmente o que acontece no ecrã (Godinho, 2007). O principal objetivo deste meio auxiliar de comunicação é apoiar os espetadores cegos ou com baixa visão no acompanhamento dos programas televisivos. Na áudio descrição, as cenas e imagens que surgem no ecrã são relatadas por um narrador alternadamente com as falas das personagens, permitindo o entendimento total da narrativa audiovisual. A áudio descrição é efetuada entre as falas e em sincronia com outras informações subjacentes à narrativa: expressões faciais, indumentária e ambiente. Desta forma, esta técnica de apoio não se sobrepõe ao conteúdo sonoro, mas opera com este no sentido de propiciar o melhor entendimento de uma cena (Figura 1). 
Figura 1 - Representação da áudio descrição do filme "Pátio das Cantigas"

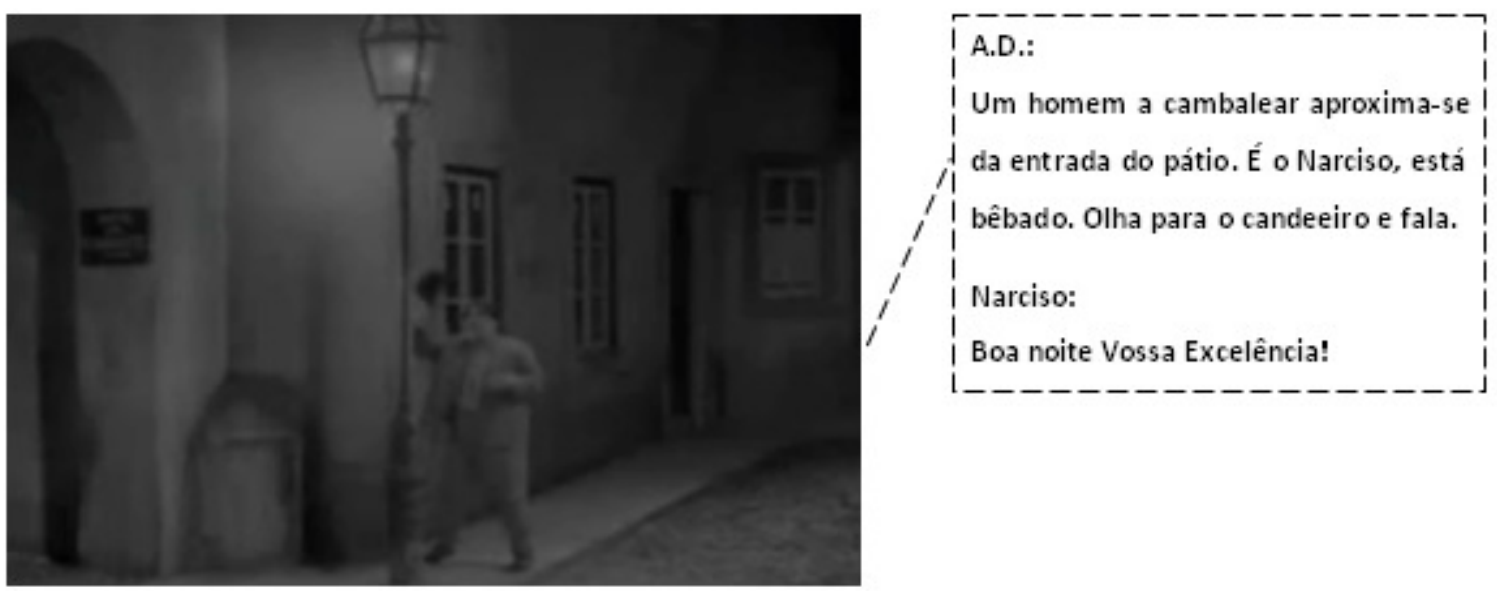

Deste modo, o processo de produção de áudio descrição obedece a várias etapas sequenciais específicas (Audiodescrição.com, s/d):

- Estudo e Guião: Um áudio descritor especializado estuda a obra a ser descrita e produz um guião com os textos a serem narrados, que segue normas específicas.

- Ensaios e ajustes: Depois do guião pronto, o áudio descritor deverá ensaiar a colocação das descrições nos locais previamente escolhidos. Para além disso, são também efetuados ajustes de tempo e/ou a troca de vocabulário.

- Gravação: Nesta fase, o áudio descritor entra em estúdio com o diretor de gravação e com um técnico, para executar a gravação das descrições contidas no guião.

- Sincronização: O ficheiro de áudio gravado é editado e associado à banda sonora original do filme ou do programa num novo ficheiro de áudio, ou num canal áudio específico para esse fim.

\section{2. $\mathrm{Na} W e b$}

A SMIL (Synchronized Multimedia Integration Language) é uma linguagem de marcas poderosa, direcionada para o ambiente Web e definida pelo W3C 
(World Wide Web Consortium), que permite a introdução de áudio descrições mais longas do que aquelas que normalmente os intervalos entre os diálogos e o conteúdo audiovisual suportam (Técnicas para as WCAG 2.0, 2008). Através da SMIL, os ficheiros de áudio e de vídeo são divididos em vários ficheiros que são reproduzidos sequencialmente; no entanto, a última frame dos ficheiros de vídeo é parada, de modo a permanecer no ecrã enquanto o ficheiro de áudio continua a ser reproduzido. O resultado final consiste num vídeo que parece ser reproduzido normalmente, mas, na verdade, é parado nas alturas em que é fornecida uma áudio descrição mais alargada. Após a áudio descrição ser efetuada, o vídeo avança automaticamente.

Alguns exemplos de leitores que suportam a linguagem SMIL são: i) Adobe Media Player; ii) QuickTime Player; iii) RealPlayer; iv) Windows Media Player; e v) Zune.

\subsection{No Cinema}

A disponibilização de áudio descrição em salas de cinema pode ser dividida em dos tipos: i) AD em sinal aberto; e ii) AD em sinal fechado (Neves, 2011).

A áudio descrição em sinal aberto implica menores custos em relação à segunda forma de transmissão, no entanto obriga a que todas as pessoas presentes na sala de cinema ouçam a áudio descrição, independentemente de a querem ouvir ou não, para além de não ser constantemente disponibilizada.

Por outro lado, a áudio descrição em circuito fechado, recorrendo a transmissores e a auriculares, torna-se numa solução mais adequada e eficiente, já que permite que o serviço de $A D$ seja utilizado em qualquer sessão, sendo não-intrusiva, pois na mesma sala de cinema podem estar pessoas que não queiram utilizar a $A D$, sem que sejam incomodas por ela. 


\subsection{No Teatro}

A áudio descrição no teatro obedece a métodos diferentes daqueles que são implementados em salas de cinema, apesar de se utilizarem também sistemas de transmissão de sinal fechado (Neves, 2011).

Por ser um espetáculo feito em direto, não é possível utilizar áudio descrições pré-gravadas, o áudio descritor tem de estar presente fisicamente. Normalmente, o áudio descritor encontra-se numa cabina insonorizada localizada no teatro, onde este possui vista sobre o palco ou tem acesso ao palco através de imagens televisivas (Figura 2).

Por vezes, devido ao caráter improvável da peça de teatro, o áudio descritor vê-se obrigado a adaptar a áudio descrição segundo aquilo que vai acontecendo no palco.

Figura 2 - Áudio Descritor a efetuar a $A D$ com vista para o palco $(B H, 2011)$

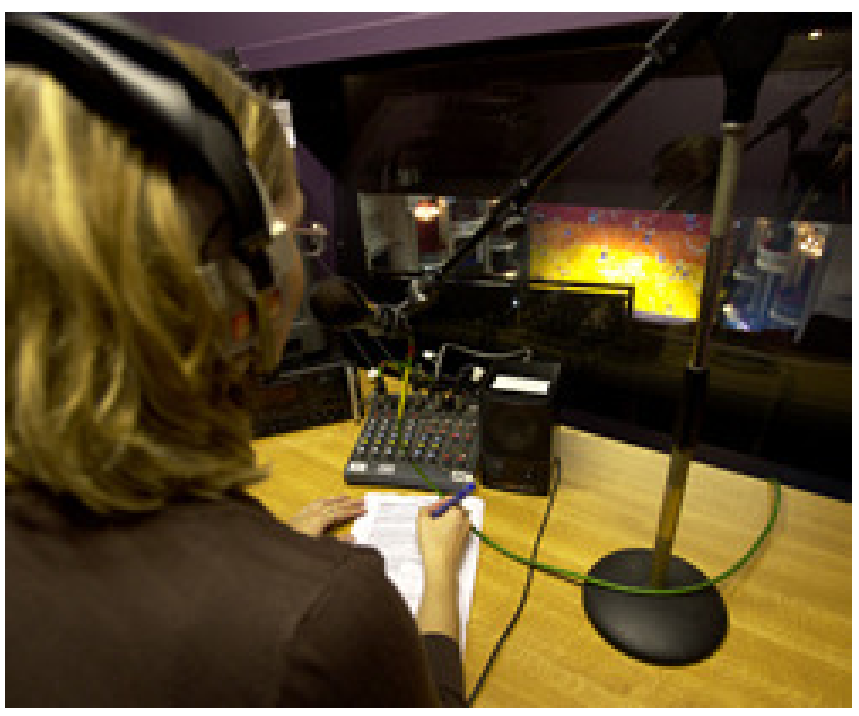

\section{A Áudio Descrição em Portugal}

Em Portugal, o primeiro programa a ser transmitido por áudio descrição foi o filme "Menina da Rádio", emitido pela RTP 1, no final do ano de 2003 (Quico, 2005). Para que seja possível ter acesso ao serviço é necessário sintonizar a Onda Média da Antena 1. Em termos práticos, o modelo subjacente a esta 
técnica consiste na utilização de uma frequência de rádio que suporta a emissão televisiva. Deste modo, o programa é transmitido normalmente através da televisão e a descrição das cenas e imagens é transmitida, em simultâneo, pela rádio.

Atualmente, os telespectadores cegos ou com deficiências visuais podem acompanhar as emissões de televisão das séries "Velhos Amigos" e "Pai à Força" através de áudio descrição transmitida na Onda Média da Antena 1 (RTP, 2011).

Em dezembro de 2004, foi lançado o serviço de áudio descrição da ZON, em parceria com os canais Lusomundo (atual TVCine) (Quico, 2005). Este foi o primeiro (e até ao momento o único) serviço destinado a pessoas com necessidades especiais difundido por um operador de televisão digital a nível nacional. O processo de áudio descrição da ZON consiste numa narração adicional à banda sonora da narrativa audiovisual. Para aceder a este serviço os clientes da ZON devem pressionar a tecla verde do comando da STB e premir 'OK' na opção 'Áudio descrição' (ZON, 2010). Para voltar a ver o programa sem áudio descrição, o utilizador deverá escolher a opção "Sem áudio descrição" que está presente no ecrã e pressionar "OK".

Em relação a outras plataformas, apenas existem dois DVD's editados em Portugal com áudio descrição e restantes meios auxiliares de comunicação (legendagem e língua gestual), sendo eles o 'O Nascimento de Cristo' e 'Atrás das Nuvens'. No cinema nenhuma iniciativa foi ainda registada, apenas a disponibilização destes dois filmes em salas de cinema.

\section{A Áudio Descrição Noutros Países}

\subsection{Brasil}

No Brasil alguns websites disponibilizam séries e pequenos filmes áudio descritos que passam igualmente na Televisão. 
Apesar de existirem alguns conteúdos televisivos com áudio descrição, ainda existem poucos. Uma das razões para que tal aconteça pode estar relacionada com a regulamentação legal para a áudio descrição na Televisão no Brasil ter acontecido há relativamente pouco tempo (ACAPO, 2010).

Em relação aos DVD's, o Brasil possui um mercado muito mais vasto em relação ao português, existindo vários filmes em DVD com áudio descrição. No que diz respeito às salas de cinema, já existem algumas salas adaptadas com circuito fechado de transmissores e auscultadores para que as pessoas com deficiência visual possam ter acesso à áudio descrição e ao próprio som do filme.

\subsection{Dinamarca}

A Dinamarca efetuou o switch-off da transmissão televisiva analógica em 2009, possuindo, atualmente, apenas o sistema de transmissão digital.

A estação televisiva DR (Danmarks Radio) fornece o serviço de áudio descrição desde 2008 (DB, 2010). A áudio descrição das narrativas audiovisuais é disponibilizada num canal temporário exclusivo (o DR synstolkning). O canal só está disponível durante a transmissão do programa com áudio descrição, tanto via TDT como via cabo (através da operadora YouSee). De sublinhar que este país possui também um canal exclusivo para a interpretação gestual da programação noticiosa dos canais DR e TV2.

\subsection{Reino Unido}

O Reino Unido é o país com o mercado de áudio descrição mais desenvolvido e regulamentado. Para além disso, todas as estações de televisão são legalmente obrigadas a transmitir uma percentagem da sua programação com recurso à áudio descrição.

Apesar de não existirem normas legalmente estabelecidas para a implementação de áudio descrição no Reino Unido, existem algumas orientações fornecidas pela entidade reguladora da Comunicação do país, a 
Ofcom (The Office of Communications), que são geralmente cumpridas pelas estações televisivas.

Atualmente, no Reino Unido, existem mais de vinte modelos de televisores (com conversor de sinal digital integrado), bem como várias STB e gravadores compatíveis com áudio descrição, os quais são direcionados para as três plataformas de televisão digital: terrestre, cabo e satélite (Ricability, 2010). Nas operadoras 'Sky' (satélite) e 'Virgin Media' (cabo), a áudio descrição é combinada com a narrativa através de um canal de áudio, sendo apenas necessário alterar algumas configurações na televisão.

Em relação a filmes em DVD, o Reino Unido possui um mercado mais vasto que o brasileiro, com mais de 500 DVD's com áudio descrição. Para além disso, mais de 300 cinemas oferecem sessões de filmes com áudio descrição. Em relação ao teatro, existem muitas peças que podem ser acompanhadas por áudio descrição, língua gestual e legendas.

\subsection{E.U.A.}

Nos E.U.A., a áudio descrição foi inicialmente fornecida através de um serviço na televisão analógica chamado Second Audio Program (SAP) (ADP, 2010). Ao ativar o SAP, a partir do telecomando, o telespectador poderia receber um canal áudio secundário que substituía o canal áudio por defeito. Com a introdução da Televisão Digital por cabo e satélite foi designado um canal áudio para o fornecimento do serviço de áudio descrição, no entanto eram raros os fornecedores de Televisão Digital que disponibilizavam programas com áudio descrição.

Com a transição para a Televisão Digital Terrestre e consequente switch off do sinal analógico, em junho de 2009, a receção do serviço de áudio descrição foi significativamente afetada, devido à falta de iniciativa por parte da indústria televisiva (estações de televisão, fabricantes de STB, etc.) em criar condições de acesso ao canal áudio designado pela FCC (Federal Communications Commission) para a transmissão da áudio descrição (ADP, 2010). Deste modo, 
apesar do sistema digital permitir oito canais de áudio em simultâneo e um deles estar especificamente dirigido para a áudio descrição, a industria televisiva não concordou com a sua utilização. Devido a estas razões, as estações não disponibilizam programas com áudio descrição e não estão à venda equipamentos com a capacidade de difusão do canal.

\section{Serviços iTV de Áudio Descrição}

Apesar de ter havido um esforço, especialmente por parte do Reino Unido, em tornar a Televisão acessível a UDV, ainda são poucos os serviços iTV de áudio descrição. Nesta secção são abordados alguns desses serviços, nomeadamente duas soluções comerciais do Reino Unido.

\subsection{Sky Audio Description}

A empresa britânica de Televisão por Satélite 'Sky' aumentou, recentemente, a quantidade de programas com áudio descrição em $20 \%$ nos seus canais, com a exceção dos canais 'Sky Sports' e 'Sky News', já que os programas destes canais apresentam narrativas audiovisuais não compatíveis com a áudio descrição, designadamente jogos de variadas modalidades desportivas e programas noticiosos e de informação (Sky, 2009a).

Os assinantes do serviço TV 'Sky' podem aceder às listagens de todos os programas com áudio descrição para os 7 dias seguintes no website da 'Sky' ou, em alternativa, podem contactar a empresa via correio postal ou via e-mail para requer essas mesmas listagens. Outra forma para saber que programas utilizam áudio descrição é através do serviço "Audio Narrative Beep" que permite aos utilizadores invisuais identificarem claramente quando uma faixa de áudio descrição se encontra disponível para o programa que está a ser transmitido no momento (Sky, 2009b).

Os utilizadores do serviço TV 'Sky' podem ainda configurar a áudio descrição para uso permanente ou temporário, sendo que os passos que devem seguir para a ativação desta funcionalidade, em diferentes STB, são descritos abaixo (Sky, 2009b). 
Para configurar o serviço de áudio descrição permanentemente numa STB 'Sky

Digibox' e numa 'Sky+', os utilizadores devem:

- Pressionar o botão "Serviços" do comando TV;

- Pressionar o botão número '4' para selecionar a opção "Configuração de Sistema";

- Pressionar a tecla número '3' para selecionar a opção "Idiomas e Legendas";

- Selecionar a opção "Narrativa", usando as setas direcionais esquerda/direita para mudar entre "ON" e "OFF";

- Selecionar a opção "Guardar Alterações" e pressionar o botão "Selecionar".

Para configurar permanentemente o serviço de áudio descrição numa STB 'Sky+ HD', os utilizadores devem:

- Pressionar o botão "Menu" do comando TV;

- Selecionar a opção "Opções" no primeiro menu;

- Depois selecionar a opção "Legendas" no menu do meio;

- Selecionar a opção "Áudio Descrição on/off” e alterar para "On”.

Para configurar temporariamente o serviço de áudio descrição sem passar pelo menu de "Idioma" (Skydigibox e sky+box) e "Legendas" (sky+HD), os utilizadores devem:

- Pressionar o botão "Help" no comando TV;

- Usar as teclas direcionais cima/baixo até selecionar a opção "Narrativa";

- Pressionar as teclas direcionais esquerda/direita para alterar para "ON"; 
- Pressionar o botão "Select" do comando TV;

- Se não estiver disponível nenhuma áudio descrição para aquele programa, a mensagem "Indisponível" aparecerá no ecrã.

Através da identificação dos passos que o utilizador necessita de efetuar para configurar este sistema de áudio descrição, é notória a grande quantidade de informação visual com que o UDV tem de lidar. Este facto é relevante, na medida em que é de grande importância a aplicação de estratégias para simplificar o acesso e a configuração deste tipo de sistemas. De seguida, são apresentados outros sistemas, que pretendem reduzir estas dificuldades de acesso

\subsection{Smart Talks}

A 'Smart talks' é uma STB que lê ao utilizador todas as informações presentes no ecrã, incluindo guias de programação e menus, através de um sistema de síntese de discurso. Esta STB foi conceptualizada e desenvolvida em conjunto com o RNIB (Royal National Institute of Blind People) para fornecer a pessoas com deficiência visual, o acesso sem condicionamentos aos canais Freeview (empresa britânica que fornece canais free-to-air na TV digital) (RNIB, 2010a).

Como é sabido, a áudio descrição não se encontra disponível em todos os programas e por esse motivo com a 'Smart Talks' os utilizadores podem perceber se ela se encontra disponível através da barra de programação, onde a palavra "AD" é mostrada. Para além disso, os utilizadores podem ouvir a informação acerca do programa que estão a ver pressionando apenas a tecla "info" do comando TV. Outra forma de aceder à informação de um determinado programa é através da barra de programação, para isso é necessário pressionando a tecla "info" no canal pretendido.

O serviço de áudio descrição não está ligado por omissão, sendo necessário configurar a sua ativação/desativação, para isso os utilizadores devem pressionar a tecla "AD" no comando TV. Para além desta opção, os utilizadores podem também aceder a funcionalidades avançadas relacionadas com a áudio 
descrição. Seguidamente são explicados os passos que os utilizadores devem seguir (RNIB, 2010b):

- Pressionar a o botão "Menu" do comando TV; a opção "Preferências" (como é a primeira da lista) fica realçada e é apenas necessário pressionar o botão "OK" (Figura 3);

Figura 3 - Primeiro ecrã do menu de opções da STB 'Smart Talks'

\section{Main menu}

\section{Preferences}

2. Favourites

3. Parental control

4. Reminders list

5. Technical settings

6. Help

0 . System information

A $\sqrt{\nabla}$ Next/previous OK Select menu

- Selecionar a opção "Preferências de Áudio Descrição" e usar as teclas direcionais cima/baixo para escolher a opção "Ligar AD ON/OFF" ou "Ligar Alerta AD ON/OFF";

- Se a opção "Ligar AD ON/OFF" for selecionada é necessário usar as teclas direcionais cima/baixo para escolher entre as opções "Ligar AD" ou "Desligar $A D " ;$

- Se a opção "Ligar Alerta AD ON/OFF" for selecionada é necessário usar as teclas direcionais cima/baixo para selecionar se quer ou não ser sempre alertado quando um programa tenha disponível áudio descrição (esta 
informação aparecerá na barra de informação do programa). Com esta opção ativada, a 'Smart Talks' emite um duplo beep sempre que haja áudio descrição disponível.

\section{Identificação de Utilizadores}

As pessoas possuem uma necessidade intrínseca de se diferenciar das restantes com o objectivo de se individualizar. Esta é uma característica que se mostra, provavelmente, antes da consciência da pessoa em si. Para Leibniz (1979) "na Natureza nunca há dois seres perfeitamente idênticos, onde não seja possível encontrar uma diferença interna, ou fundada em uma denominação intrínseca". Quando os indivíduos passam a ter consciência, a individualização passa a ser entendida de uma nova forma. As pessoas passam a entender-se como diferentes, a criar as suas próprias bases de sentidos, ideias e conceitos, ou seja, passam a conhecer-se a si (Chauí, 2000). A identificação do indivíduo para si e para a comunidade faz parte das suas fases evolutivas e são uma necessidade para o convívio em sociedade, pois cada um precisa de ser reconhecido num universo de milhões, para se elevar em todos os aspetos da vivência humana.

Para Chauí (2000) qualquer Ser existe, apenas, se não for dissociado da sua identidade que é, normalmente, analisada segundo dois aspetos: i) o associado à identidade psíquica; ii) e o associado a algo mais tangível como os detalhes biológicos da individualidade humana.

Assim, o processo "identificação" pode ser descrito como uma reunião de métodos e sistemas para se reconhecer uma pessoa, que se baseia nas suas características ou em algo que possua, para efetuar a identificação.

\subsection{Identificação de utilizadores em televisão}

Os televisores são equipamentos que, normalmente, são utilizados simultaneamente por vários utilizadores, o que complica a tarefa de disponibilizar conteúdos e serviços personalizados, como por exemplo a publicidade direcionada. Se um utilizador atuar em representação de um grupo 
(identificado por exemplo pela STB que está numa determinada casa), por certo que, resultarão perdas na qualidade de personalização. Assim, entregar anúncios direcionados, propor um conteúdo, ajustar preferências de visualização, são funcionalidades que não estarão completamente afinadas para um determinado utilizador, pois os utilizadores são agregados num único perfil.

A identificação pode ser feita de duas formas: i) explicita, na qual os utilizadores, explicitamente, fornecem os dados de identificação, podendo-lhes ser perguntado, periodicamente, quem está a ver TV ou se alguém saiu da sala entretanto. Esta forma degrada a experiência de utilização, pois existe uma interrupção da visualização de conteúdos; e ii) implícita, na qual o utilizador é identificado sem fornecer explicitamente informação ao serviço. A informação deste modo de identificação pode ser inferida, por exemplo, com base nas diversas interações do utilizador (canal escolhido, hora de visualização, volume preferencial, etc.) ou com base no reconhecimento de algo que o utilizador possua, por exemplo através de uma tag ativa RFID (RFID.org, 2011).

Existem alguns trabalhos em torno da deteção e identificação de utilizadores, tanto no âmbito académico como de âmbito mais comercial. O serviço TiVO pede os dados de identificação ao utilizador, dados esses que podem ser introduzidos através de um teclado virtual, permitindo depois o acesso a serviços personalizados.

A Austria Telekom (2010) disponibiliza um controlo remoto para televisores com identificação através da impressão digital. Estes sistemas, dadas as suas características (recolha de dados biométricos) têm uma elevada percentagem de acerto na identificação quando comparados com outros baseados noutro tipo de sensores. O elevado grau de acerto, o facto de usar informação sensível e indissociável de um indivíduo, a elevada segurança e fiabilidade, permite que os dados de identificação possam ser utilizados para autorizações em sistemas sensíveis, como bancos e compras. Além da utilização das impressões digitais, existem outras abordagens para a identificação dos utilizadores, como o processamento de imagem para efetuar deteção e 
reconhecimento de faces, proposto em Hwang, Ha et al. (2007). Este tipo de solução não obriga o utilizador a inserir dados, pelo que maximiza a facilidade de interação. No entanto, este tipo de sistemas pode induzir nos utilizadores uma sensação de perda de privacidade, uma vez que as câmaras associadas aos televisores podem estar a captar o que se passa nas salas de estar, quartos, entre outros locais da casa.

Chang et al. (2009) caracteriza uma plataforma de identificação que utiliza acelerómetros colocados em controlos remotos para perceber quem está à frente do televisor. Este sistema analisa o manuseamento do controlo remoto e, com base nesses dados, infere qual é o utilizador.

Outro tipo de tecnologias utilizadas para identificar utilizadores são aquelas que se baseiam em sensores de RFID. Por exemplo, em Jabbar, Taikyeong et al. (2008) é apresentada uma aplicação dos sensores RFID para identificar e autenticar os espectadores, permitindo-Ihes aceder a serviços interativos e personalizados de uma infraestrutura de televisão.

Existem outros trabalhos como o de Philipose et al. (2004) que utilizam braceletes com identificadores RFID para perceber com que objetos os indivíduos interagem e, assim, inferir eventos das suas vivências e, consequentemente, oferecer serviços iTV mais personalizados.

A identificação dos utilizadores pode, ainda, ser feita através de dispositivos Bluetooth (Bluetooth SIG, 2010). Este esquema de identificação é patenteado em Dawson, Hofrichter et al. (2010) e pode ser utilizado para identificar espectadores dos sistemas de iTV, bastando para tal que um utilizador tenha um identificador Bluetooth consigo e que o sistema de iTV seja capaz de reconhecer o identificador e consequentemente carregar um perfil.

Park et al. documentaram em Youn-Kyoung, Sun-Hee et al. (2008) um sistema que, empregando uma rede de comunicações móveis e um leitor de smart cards (Alliance, 2010), identificava os utilizadores de uma plataforma de IPTV. Assim conseguiam armazenar as preferências de um utilizador, como nível de 
som, brilho e cor da imagem, o nível de experiência do utilizador (entre outros dados), num cartão com capacidades de armazenamento.

O reconhecimento de voz é atualmente uma peça importante em vários componentes da nossa vida quotidiana. Os telefones móveis, os sistemas de navegação dos automóveis e os computadores são apenas alguns exemplos. A ligação deste tipo de componentes aos sistemas de televisão interativa aparece como mais uma hipótese para realizar a identificação de utilizadores.

No âmbito comercial, enunciam-se de seguida alguns exemplos:

i) A empresa Oki Electric Industry Co Ltd desenvolveu uma tecnologia que permite determinar a idade e o género de uma pessoa que está em frente ao televisor, através de um sensor de vídeo externo. O objetivo da organização é que a tecnologia seja utilizada para direcionar a publicidade ao público, considerando a idade e o género dos espetadores. No entanto, atualmente, o sistema permite apenas ligar e desligar os televisores de acordo com a existência de utilizadores em frente ao televisor, para poupar energia. O sensor de vídeo em que a tecnologia se baseia é composto por uma pequena câmara de vídeo comercial e pelo software "Signage Eye" (Oki, 2011). Este software determina a idade e o género dos utilizadores, através do reconhecimento facial. Este software foi desenvolvido, essencialmente, para o mercado dos produtos de marketing e está a ser utilizado em lojas de conveniência para direcionar os vídeos promocionais de acordo com o perfil do comprador.

ii) A Sony disponibiliza aos seus clientes televisores capazes de identificar a presença de espectadores na sala, sendo que, caso eles saiam, o televisor desligar-se-á automaticamente. A tecnologia baseia-se na identificação de existência de caras no compartimento da casa através da análise da imagem capturada por uma câmara incorporada no televisor.

iii) A Toshiba foi um pouco mais além e consegue identificar caras e, assim, reconhecer utilizadores (Chacksfield, 2011). O televisor, através de uma câmara incorporada, consegue identificar até quatro utilizadores por casa, 
permitindo que estes construam um perfil com personalizações ao nível do EPG (Electronic Program Guide), das definições de visualização, entre outros.

\section{Processo de Investigação}

A amostra que integra esta investigação foi selecionada aleatoriamente a partir de utentes da consulta de baixa visão do Instituto de Oftalmologia Dr. Gama Pinto (IOGP, 2011), em Lisboa, com o auxílio de um médico oftalmologista. No total, 20 sujeitos com deficiência visual aceitaram ser entervistados; 10 deles eram cegos e os restantes 10 tinham baixa visão (desde utentes quase cegos a utentes que fazem uso de óculos para aumentar a sua acuidade visual).

No que diz respeito à idade dos utentes, cinco sujeitos tinham entre 10 a 18 anos, três tinham entre 19 a 34 anos, sete tinham entre 35 a 60 anos e finalmente, cinco tinham mais de 60 anos de idade. O gráfico 1 ilustra a relação entre a idade e o tipo de deficiência visual da amostra.

Gráfico 1 - Número de entrevistados por idade e tipo de deficiência visual

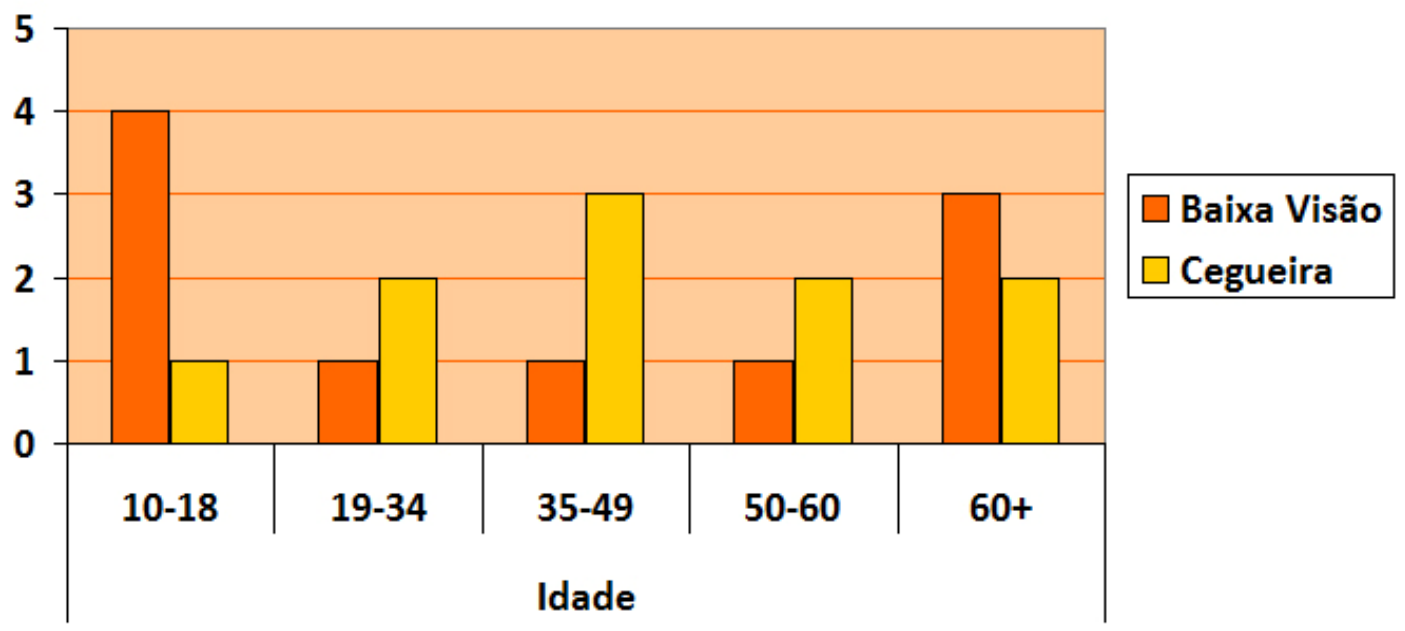

Em relação à técnica de recolha de dados, foi realizada uma entrevista semiestruturada para inferir as opiniões dos sujeitos acerca da atividade de ver televisão, nomeadamente os seus problemas de acesso e a sua experiência televisiva em termos de acesso e uso. 
Este tipo de entrevista foi escolhida, não só para facilitar o processamento dos dados, como também dar aos entrevistados alguma liberdade nas suas respostas. O guião da entrevista é composto por 31 questões, maioritariamente de resposta fechada, sendo organizadas em cinco partes:

\section{- Parte 1 - Dados Gerais:}

Foi pedido a cada sujeito para identificar o seu tipo de deficiência visual (baixa visão ou cegueira); indicar há quanto tempo sofre dessa deficiência; indicar qual é a sua profissão; e, finalmente, identificar o serviço de TV que possui em casa.

\section{- Parte 2 - Padrões de Consumo Televisivos e Áudio Descrição:}

Nesta segunda parte, os sujeitos foram questionados acerca dos seus padrões de consumo televisivos (por exemplo, quanto tempo por dia passam a ver televisão) e dos seus conhecimentos acerca da áudio descrição (por exemplo, se têm conhecimento deste meio auxiliar de comunicação e se alguma vez 0 usou).

\section{- Parte 3 - Problemas de Acesso Televisivo:}

Duas questões abertas foram colocadas ao entrevistado para que indicasse as suas dificuldades como consumidor de conteúdos televisivos e quais as estratégias/soluções para que esses problemas fossem resolvidos. Quando o sujeito não fornecia muito feedback, o entrevistador dava algumas sugestões para a resolução dos problemas relatados.

\section{- Parte 4 - Televisão Digital Terrestre e Televisão Interativa:}

Nesta parte da entrevista, os sujeitos foram questionados acerca do seu conhecimento sobre Televisão Interativa (por exemplo, se alguma vez tiveram contacto com algum sistema de iTV e, em caso afirmativo, para que fins 0 usaram), como também acerca da utilidade de um possível sistema interativo de áudio descrição com funcionalidades avançadas. 


\section{- Parte 5 - Identificação Automática}

$\mathrm{Na}$ parte final da entrevista, os entrevistados foram questionados acerca da utilidade de um sistema televisivo que detestasse automaticamente os seus utilizadores. Para além desta questão, era também perguntado ao sujeito qual o método de identificação que preferiria (por exemplo, nome de utilizador e password, cartão RFID, reconhecimento facial, etc.).

\subsection{Resultados das Questões da Parte 5: Identificação Automática}

Como foi referido anteriormente, na Parte 5 da entrevista foram colocadas duas questões ao entrevistado. A primeira era de resposta semiaberta e a segunda de resposta fechada, sendo apresentadas seguidamente:

5.1. Acharia útil se o serviço de áudio descrição detetasse e identificasse automaticamente a pessoa que o utilizasse (na prática todas as opções que o utilizador mudasse no sistema estariam sempre guardadas e seriam carregadas quando ele entrasse no sistema)? Porquê?

\subsection{Qual o método de identificação (entrada no sistema) que preferiria?}

- Nome de utilizador + Password

- Cartão RFID (cartão único com dispositivo eletrónico integrado)

- Pulseira RFID (pulseira única com dispositivo eletrónico integrado)

- Bluetooth no Telemóvel

- Leitor de impressões digitais

- Reconhecimento Facial

Em relação à pergunta $5.1,95 \%$ dos sujeitos responderam que consideravam útil um serviço de áudio descrição que identificasse automaticamente os utilizadores. Quando foi perguntado quais os motivos que os levavam a pensar 
que um sistema deste tipo seria útil, a resposta foi unânime, todos os sujeitos consideraram que o sistema tornava simples e fácil a tarefa de mudar as configurações, quando uma outra pessoa pretendesse utilizar também 0 sistema. Para além disso, 53\% destes sujeitos também afirmaram que a criação de um perfil pessoal onde eram guardadas as suas configurações era uma mais-valia para a sua experiência de utilização.

Os restantes $5 \%$ dos entrevistados afirmaram que não achariam útil um sistema deste tipo, porque vivem sozinhos e quem utiliza o televisor são somente eles.

Logo após o entrevistado responder à questão 5.1, era colocada a questão 5.2. Antes de ser colocada, o entrevistador tinha a preocupação de explicar cada um dos métodos que o sujeito podia escolher, a partir de uma lista. De realçar, também, que a ordem dos métodos na lista apresentada, não era sempre a mesma, para que os resultados não fossem influenciados pela posição que os métodos ocupavam na lista.

No que diz respeito aos resultados da questão 5.2, num total de seis métodos possíveis, os sujeitos optaram apenas por três: Cartão RFID, Leitor de Impressões Digitais e Reconhecimento Facial, pelo que os métodos Nome e Password, Pulseira RFID e Bluetooth através do Telemóvel não foram escolhidos por nenhum sujeito (Gráfico 2).

De entre os métodos de preferência dos utilizadores, o Cartão RFID foi aquele que obteve uma maior percentagem, $63 \%$. Os restantes dois métodos, o Leitor de Impressões Digitais e o Reconhecimento Facial, obtiveram 32\% e 5\%, respetivamente (Gráfico 2 ). 
Gráfico 2 - Preferência dos sujeitos pelos métodos de identificação

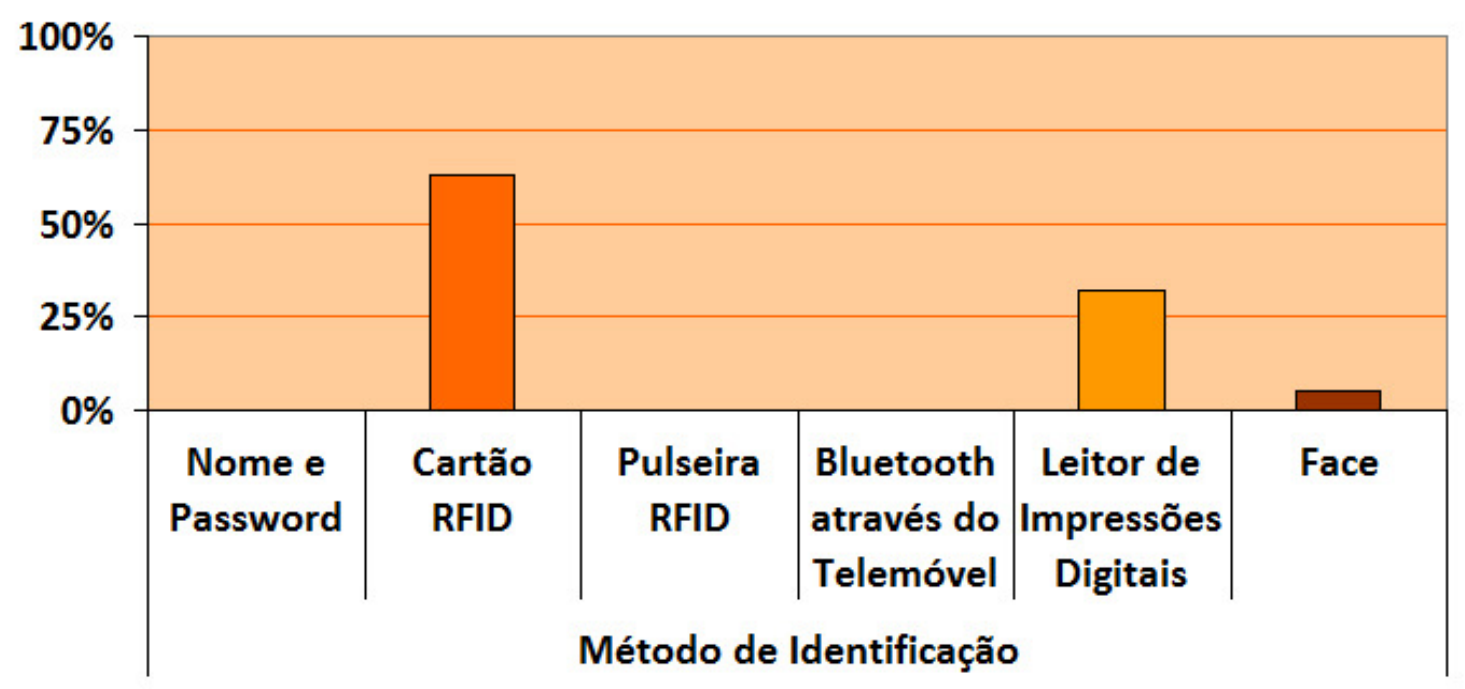

\section{Conclusões}

Com esta investigação, pretende-se promover a inclusão digital dos consumidores televisivos com deficiência visual através da utilização de um serviço de áudio descrição, baseado na identificação automática dos utilizadores, num contexto de iTV.

Desta forma, tenciona-se que este serviço esteja em conformidade com princípios de design universal e, consequentemente, que responda às reais dificuldades sentidas pelos utilizadores. Assim, para além de funcionalidades avançadas como a alteração do tamanho do texto e do esquema de cores e o controlo de opções associadas à áudio descrição, pretende-se que o sistema identifique automaticamente o utilizador que o está a utilizar, assumindo as preferências que este selecionou nas configurações do serviço. Em relação a ao processo de identificação, este pode ser efetuado através de diferentes métodos, como foi referido anteriormente.

No caso particular deste artigo, foram apresentados os resultados relacionados com os métodos de identificação que os utilizadores com deficiência visual preferem utilizar num serviço de áudio descrição. A partir destes resultados foi 
possível concluir que existe uma preferência por dois métodos de identificação, nomeadamente o uso do cartão RFID e do Leitor de Impressões Digitais.

Presentemente, através dos resultados obtidos com 0 processo de investigação descrito anteriormente, está a ser implementado um protótipo de um serviço iTV avançado de áudio descrição, que será, posteriormente, avaliado por utilizadores com baixa visão e cegos através de testes de acessibilidade e usabilidade.

\section{Agradecimentos}

Gostaríamos de deixar o nosso agradecimento: ao Instituto Oftalmológico Dr. Gama Pinto, por nos permitir realizar a entrevista aos seus utentes da consulta de sub-visão; aos entrevistados, pela sua disponibilidade e simpatia; e aos coordenadores e colaboradores do Projeto iNeighbourTV, financiado pela Fundação para a Ciência e a Tecnologia (PTDC/CCI-COM/100824/2008).

\section{Referências Bibliográficas}

Associação dos Cegos e Amblíopes de Portugal (ACAPO) (2010). ACAPO Actual, Boletim Informativo Mensal da ACAPO, N. 18 - Julho de 2010, http://www.acapo.pt/acapo-actual/acapo-actual-n-18-julho-2010, acedido em 09-10-2011.

Audiodescricao.com (s/d). Como Fazemos, http://audiodescricao.com.br/ad/, acedido em 07-11-2011.

Austria Telekom (2010). Remote Control via Fingerprint, http://unternehmen.telekom.at/Content.Node/innovation/remote-controlfingerprint.php, acedido em 15-06-2010.

Birmingham Hippodrome (BH) (2011). Assessing accessibility, http://www.birminghamhippodrome.co.uk/default.asp?ld=241\&PageSubT ype=253\&sC=page29, acedido em 07-11-2011.

Bluetooth SIG (2011). The Official Bluetooth® Technology Web Site, http://www.bluetooth.com, acedido em 02-11-2011. 
Chacksfield, M. (2011). Toshiba Cevo TV face recognition tech explained: TV personalised, http://www.techradar.com/news/television/toshiba-cevo-tvface-recognition-tech-explained-940647, acedido em 02-11-2011.

Chang, K.; Hightower, J.; and Kveton, B. (2009). Inferring identity using accelerometers in television remote controls. Proceedings of the 7th International Conference on Pervasive Computing, pp. 151-167.

Chauí, M. (2000). Convite à Filosofia. São Paulo: Ed. Ática.

Dansk Blindesamfund (DB) (2010). Sådan modtager du synstolkning fra DR, http://www.dkblind.dk/indsats/kultur-fritid/tv-radio-film/saadan-modtagerdu-synstolkning-dr/, acedido em 08-11-2011.

Dawson, T. P., K. Hofrichter, et al. (2010). User identification and prioritization using Bluetooth, United States Patent Application 20100103316.

Godinho, F. (2007). Acessibilidade para cidadãos com necessidades especiais nos regulamentos da televisão digital terrestre em Portugal. CERTIC: UTAD.

Hwang, M.-C., L. T. Ha, et al. (2007). Person Identification System for Future Digital TV with Intelligence. IEEE Transactions on Consumer Electronics 53(1): 218-226.

Instituto Oftalmológico Dr. Gama Pinto (2011). IOGP - Instituto de Oftalmologia Dr. Gama Pinto, http://www.institutogamapinto.com/, acedido em 10-112011.

Jabbar, H., J. Taikyeong, et al. (2008). Viewer Identification and Authentication in IPTV using RFID Technique. IEEE Transactions on Consumer Electronics 54(1): 105-109.

Leibniz, G. W. (1979). A monadologia. São Paulo: Abril Cultural.

Neves, J. (2011). Imagens que se Ouvem - Guia de Audiodescrição. Instituto Politécnico de Leiria: Leiria.

Oki (2011). Signage Eye SDK, http://www.oki.com/jp/fse/r product/signageeye/, acedido em 05-11-2011.

Philipose, M., K. P. Fishkin, et al. (2004). Inferring Activities from Interactions with Objects. IEEE Pervasive Computing 4(3): 50-57.

Quico, C. (2005). Acessibilidade e Televisão Digital e Interactiva: o caso particular do serviço de Áudio-Descrição destinado a pessoas invisuais 
ou com deficiências visuais graves, in Estratégias de Produção em Novos Media, Edição COFAC/ Universidade Lusófona de Humanidades e Tecnologias.

Rádio Televisão Portuguesa (RTP) (2011). Guia de Programação - RTP 1, http://www.rtp.pt/EPG/tv/epg-dia.php?title=RTP-1, acedido em 05-112011.

RFID.org (2011). RFID (Radio Frequency Identification) Technology News Insights, http://www.rfid.org, acedido em 02-11-2011.

Royal National Institute of Blind People (RNIB) (2010a). Goodmans Smart Talk Freeview set top box, http://www.rnib.org.uk/Shop/Product\%20instructions/TV0401.doc, acedido em 08-11-2011.

Royal National Institute of Blind People (RNIB) (2010b). Smart Talk Freeview digital box from Goodmans, http://www.rnib.org.uk/shop/Pages/ProductDetails.aspx?product|D=tv040 1, acedido em 08-11-2011.

Sky (2009a). Audio description, http://accessibility.sky.com/get-the-most-fromsky/sky-tv/if-you-have-visual-impairment/audio-description, acedido em 09-11-2011.

Sky (2009b). If you have a visual impairment, http://accessibility.sky.com/getthe-most-from-sky/sky-tv/if-you-have-visual-impairment, acedido em 0911-2011.

Técnicas para as WCAG 2.0 (2008). SM6 - Fornecer uma áudio-descrição em SMIL 1.0, http://www.acesso.umic.pt/w3/TR/WCAG20-TECHS/SM6.html, acedido em 07-11-2011.

The Audio Description Project (ADP) (2010). Audio Description (Video Description) on TV, http://www.acb.org/adp/tv.html, acedido em 09-112011.

Tiresias (2011a). Television - Interactive Digital Television, http://www.tiresias.org/research/guidelines/television/idtv.htm, acedido em 05-11-2011. 
Tiresias (2011b). Television - Future access services, http://www.tiresias.org/research/guidelines/television/future access servi ces.htm, acedido em 05-11-2011.

Youn-Kyoung, P., L. Sun-Hee, et al. (2008). User Authentication Mechanism Using Java Card for Personalized IPTV Services. Proceedings of the 2008 International Conference on Convergence and Hybrid Information Technology, pp. 618-626.

ZON Multimédia (ZON) (2010). Responsabilidade Social, http://www.zon.pt/Clientes/DetalheClientes.aspx?detail=XzU495, acedido em 08-11-2011.

Para citar este artículo

Oliveira, Rita - Silva, Telmo - Abreu, Jorge Ferraz de - Almeida, Ana Margarida (15-122011). IDENTIFICACÃO AUTOMÁTICA DE UTILIZADORES COM DEFICIÊNCIA VISUAL: A BASE PARA UM SERVIÇO DE ÁUDIO DESCRIÇÃO PERSONALIZADO.

REDMARKA - CIECID - Unidad de Investigación en Marketing Aplicado-Universidad de A Coruña

Año IV, Número 7, V3, pp.125-154

ISSN 1852-2300

URL del Documento: cienciared.com.ar/ra/doc.php?n=1606

URL de la Revista: cienciared.com.ar/ra/revista.php?wid=39 